\title{
Sites miniers en vallée de Baïgorry et vallées navarraises limitrophes
}

\section{Gilles Parent}

\section{OpenEdition Journals}

Édition électronique

URL : http://journals.openedition.org/adlfi/7567

ISSN : 2114-0502

Éditeur

Ministère de la culture

Référence électronique

Gilles Parent, « Sites miniers en vallée de Baïgorry et vallées navarraises limitrophes », ADLFI.

Archéologie de la France - Informations [En ligne], Aquitaine, mis en ligne le 01 mars 2007, consulté le 03 mai 2019. URL : http://journals.openedition.org/adlfi/7567

Ce document a été généré automatiquement le 3 mai 2019.

(C) Ministère de la Culture et de la Communication, CNRS 


\title{
Sites miniers en vallée de Baïgorry et vallées navarraises limitrophes
}

\author{
Gilles Parent
}

Identifiant de l'opération archéologique : 025118

Date de l'opération : 2007 (PT)

\section{La mine de Zebia (Monhoa)}

1 Poursuivant la campagne d'étude et de datation des anciennes mines de la région de la vallée de Baïgorry, nos efforts se sont portés essentiellement en 2007 sur les travaux de Monhoa. La montagne qui porte ce nom abrite une petite mine référencée au XVIII ${ }^{\mathrm{e}} \mathrm{s}$. pour avoir fait à cette époque l'objet d'une tentative de reprise pour cuivre sur d'anciens travaux attribués aux Romains. Cependant, deux datations obtenues en 2005 et 2006 sur des morceaux de charbon de bois issus du remplissage de l'extrémité des ouvrages supérieurs, évoquaient une exploitation au cours du II ${ }^{\mathrm{e}} \mathrm{s}$. av. J.-C.

En 2007, un sondage d' $1 \mathrm{~m}^{2}$ a été ouvert dans la zone d'entrée de la galerie principale. Une stratigraphie assez riche a été rencontrée. Deux sols sont révélés, le second, le plus profond, paraissant fortement lié à l'exploitation minière : il s'agit d'une sorte de ballast particulièrement induré recouvert d'une fine couche très oxydée. Un important fragment de charbon de bois y a été prélevé. Son âge calibré est compris entre 92 av. et 70 apr. J.-C, avec un pic de probabilité à 15 av. J.-C. Ce niveau induré, reposant sur des couches de déblais miniers, témoigne selon toute vraisemblance d'une phase d'activité qui succède à d'autres périodes d'exploitation. Ces informations conforteraient l'idée d'une première phase au cours de la fin du second âge du Fer, puis d'une seconde lors du début de la présence romaine, cette dernière période étant par ailleurs bien représentée dans les sites miniers majeurs de la vallée. 
3 Un autre sondage pratiqué dans les remblais de la salle du niveau inférieur, ouvrage en théorie postérieur aux travaux sus-jacents, a livré des charbons de bois dont l'analyse confirme la période d'activité du tout début de notre ère (43av. à 79 apr.J.-C, 2 pics à $25 \mathrm{apr}$. et $15 \mathrm{av}$. J.-C.). Les datations issues des sondages des années précédentes, les plus anciennes obtenues dans la région de la vallée de Baïgorry car révélant une exploitation antérieure à la présence romaine, nous incitent à poursuivre nos investigations dans la mine de Monhoa.

4 Une fouille de la zone d'entrée est prévue en 2008, avec dégagement de ce sol puis des niveaux sur lesquels il repose.

5 (Fig. $\mathrm{n}^{\circ} 1$ : Coupe de la minze Zebia.)

\section{Banca, travaux sur le filon de Berg-Op-Zoom}

Un sondage a été tenté à l'orifice d'une descenderie ouverte sur l'affleurement du filon de Berg-Op-Zoom. Si le sondage a révélé une stratigraphie très monotone, sans aucun indice de datation, il a cependant permis de découvrir la présence d'une tranchée de surcreusement, ici profonde de $0,80 \mathrm{~m}$ et ouverte dans la roche pour faciliter la sortie des matériaux de la mine. Ce type d'aménagement avait antérieurement été rencontré à deux reprises dans le site de Banca à l'orifice de travaux antiques en puits ou descenderie. Le dégagement total de l'entrée serait à réaliser.

\section{La mine d'Uniz, en vallée du Baztan (Navarre)}

7 La vallée du Baztan, qui borde à l'ouest celle de Baïgorry, est particulièrement riche en vestiges miniers. Une tentative de datation avait été menée en 2006 dans un petit site montrant des indices spectaculaires de cuivre. L'obtention toujours très tardive des autorisations locales (fin octobre ou novembre, etc.) nous laisse généralement peu de temps pour développer ces recherches. Un ouvrage souterrain en descenderie a fait l'objet en 2007 d'un début de désobstruction, montrant par endroits un modelé de taille au feu ainsi que des perforations pour le tir à l'explosif. Découvrir dans cette région des travaux sur des filons cuprifères vierges de toute reprise moderne est une gageure, situation conséquente de la recherche fiévreuse qui s'y déroula dans la première moitié du XVIII ${ }^{e}$ s. La poursuite de ce dégagement est prévue pour 2008.

Parent Gilles

\section{ANNEXES}


Fig. $\mathrm{n}^{\circ} 1$ : Coupe de la minze Zebia.

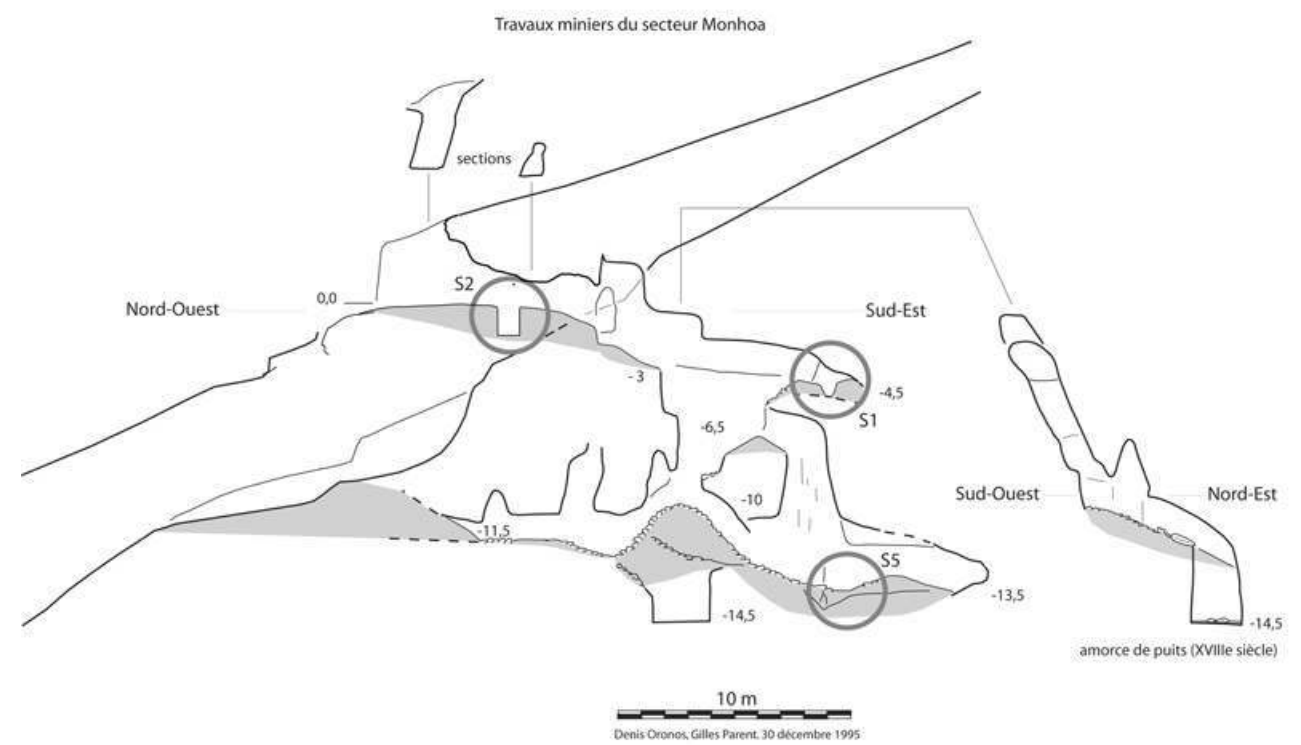

Cronos Denis ; Parent Gilles (2007)

INDEX

operation Prospection thématique (PRT)

Index chronologique : âge du Fer, Haut-Empire

Thèmes : charbon de bois, cuivre, datation isotopique, mine, stratigraphie

Index géographique : Aquitaine, Pyrénées-Atlantiques (64), Banca

\section{AUTEURS}

\section{GILLES PARENT}

BEN 